DOI https://doi.org/10.30525/978-9934-26-075-9-7

\title{
THE AGGRAVATING EFFECT OF COMORBIDITY OF PRIMARY OSTEOARTHRITIS AND DISEASES WITH EXOCRINE PANCREATIC INSUFFICIENCY
}

\author{
Halabitska I. M. \\ PhD, MD, Assistant Professor, \\ I. Horbachevsky Ternopil National Medical University \\ Babinets L. S. \\ DMSci, PhD, MD, Professor, \\ I. Horbachevsky Ternopil National Medical University \\ Ternopil, Ukraine
}

According to the World Health Organization (WHO), more than $40 \%$ of the elderly suffer from OA, up to $80 \%$ of OA patients have limited mobility, and $25 \%$ are unable to do regular household chores. Lesions of the gastrointestinal tract (GIT), accompanied by a decrease in excretory function of the pancreas (PF), are frequent pathological processes that accompany primary OA as comorbid conditions [1-5].

The excretory insufficiency of pancreas in patients with primary osteoarthritis is formed at the comorbid pathologies and as a result of longterm treatment of osteoarthrosis using the non-steroidal anti-inflammatory drugs, steroids, chondroprotectors and chondrostimulators etc. Inflammation plays significant part in the pathogenesis of osteoarthritis. The main mechanism of cartilage degradation are production of proinflammatory cytokines (IL-1 $\beta$, IL-6, FNP- $\alpha$, etc.). They release enzymes that damage collagen (collagenase, elastase, peptidase) and proteoglycans (metalloproteinases, stromelysin, cathepsins) and activate proteolytic activity. This leads to increased destruction of hyaluronic fibers and a decrease cartilage regeneration [1-5].

Pathological changes in the digestive system can develop against the background of treatment of primary OA, especially long-term use of nonsteroidal anti-inflammatory and other groups of drugs used to reduce the intensity of pain and inflammation, as well as for chondroprotection and chondrostimulation [1-5].

The purpose of the study: to study the parameters of joint pain and their relationship with indicators of the excretory function of the pancreas in patients with primary $\mathrm{OA}$ with comorbid conditions. 
Materials and methods. We examined 174 outpatients with primary OA in combination with diseases accompanied by a decrease in excretory function of the pancreas in a state of complete and incomplete clinical remission: chronic pancreatitis, chronic non-stone cholecystitis, functional diseases of the gastrointestinal tract. The mean age of patients was (57.4 \pm 6.3$)$ years (from 26 to 79 years); there were 86 women (49.4\%) and 88 men (50.6\%). The control group consisted of 30 healthy people. Exclusion criteria were cancer, acute, and exacerbation of chronic pathologies of vital organs, severe diabetes, type 1 diabetes, active gastric and duodenal ulcers, viral hepatitis and liver cirrhosis, Crohn's disease, nonspecific ulcerative colitis, cystic fibrosis.

The diagnosis of OA was established on the basis of diagnostic criteria of the ACR and the European Association of Rheumatologists (European League Against Rheumatism, EULAR, 2018). Examination of the joints included examination, palpation, and objective assessment of pain at rest and during VAS movements.

The fecal $\alpha$-elastase content was determined to assess the state of the secretory function of the pancreas. Fecal $\alpha$-elastase was determined by enzyme-linked immunosorbent assay using standard BIOSERV ELASTASE 1-ELISA kits.

Student's $t$ test was used in the processing of statistical data in the parametric distribution. Non-parametric tests were used for the populations whose distribution differed from the "normal" one: to compare two independent samples, the Mann-Whitney U-test was used. Analysis of the relationship between the two traits in the presence of a normal distribution was evaluated by the results of Pearson correlation analysis (r), with a distribution other than normal, used a nonparametric Spearman rank correlation method (R).

Research results and their discussion. Analysis of the obtained indicators of fecal $\alpha$-elastase content of patients showed a decrease in excretory function of the pancreas in the study group - $(64.24 \pm 5.85) \mu \mathrm{g} / \mathrm{g}$ - compared with the control group $(212.71 \pm 4.65) \mu \mathrm{g} / \mathrm{g})(\mathrm{p}<0.05)$. The indicator of VAS at rest was $(25.54 \pm 3.42) \mathrm{mm}$, the indicator of VAS at movements $-(38.81 \pm 4.41)$ $\mathrm{mm}$.

Correlation and regression analysis of indicators of excretory function of the pancreas by the content of fecal $\alpha$-elastase, the quantitative value of changes in the coprogram, expressed in points, with the pain index according to VAS.

Table 1 - Correlation between the indicators of excretory function of the software and the articular indices of VAS (r) 


\begin{tabular}{|c|c|c|}
\hline Regression pairs & $\begin{array}{c}\text { VAS index, calm, } \\
\mathrm{mm}(\mathrm{n}=174)\end{array}$ & $\begin{array}{c}\text { VAS index, } \\
\text { movements, } \mathrm{mm} \\
(\mathrm{n}=174)\end{array}$ \\
\hline Fecal $\alpha$-elastase, $\mu \mathrm{g} / \mathrm{g}$ & $-0,463$ & $-0,489$ \\
$\mathrm{p}<0,05$ & $\mathrm{p}<0,05$ \\
\hline
\end{tabular}

It was found that there are statistically significant correlations between the pairs of correlations, which indicates the influence of exocrine insufficiency of the pancreas on the course of primary OA $(\mathrm{p}<0.05)$.

Conclusions. The identified correlations proved the interdependence and severity between the decrease in excretory function of the pancreas and the severity of joint pain in patients with primary OA.

\section{Reference:}

1. Babinets, L.S., Halabitska, I.M. Chronic inflammatory process and bone tissue changes in patients with osteoarthritis and exocrine pancreatic insufficiency, 2020, Lekarsky Obzor, 69 (1), Pp. 7-10.

2. Tella S.H., Gallagher J.C.: Prevention and treatment of postmenopausal osteoporosis. Journal of Steroid Biochemistry and Molecular Biology, 2014, 142, Pp. 155-170.

3. De LA Iglesia-García D., Huang W., Szatmary P., Baston-Rey I., Gonzalez-Lopez J., Prada-Ramallal G., Mukherjee R., Sutton R.: Efficacy of pancreatic enzyme replacement therapy in chronic pancreatitis: Systematic review and meta-Analysis. Gut, 2017, 66 (8), Pp. 1474-1486.

4. Babinets L.S., Halabitska I.M., Kotsaba Y.Y. et al. The effect of the proteolisis' system activity for the trophological status of patients with osteoarthritis and exocrine insufficiency of pancreas. Wiadomosci lekarskie (Warsaw, Poland: 1960) 2018; 71(2 pt 1): 273-276.

5. Babinets, L.S., Kytsai, K.Y., Kotsaba, Y.Y. et al. Improvement of the complex medical treatment for the patients with chronic biliary pancreatitis Wiadomosci lekarskie (Warsaw, Poland:1960), 2017; 70(2): 213-216. 